\title{
Successful Medical Treatment of Hyperinsulinemic Hypoglycemia in the Adult: A Case Report and Brief Literature Review
}

\author{
Vania Gomes $^{\mathrm{a}, \mathrm{b}}$, Florbela Ferreira ${ }^{\mathrm{a}}$
}

\begin{abstract}
Hyperinsulinemic hypoglycemia is characterized by inappropriate insulin secretion from the pancreatic $\beta$ cells causing low blood glucose levels. Nesidioblastosis is a very rare cause of hyperinsulinemic hypoglycemia in adults. Medical therapy can effectively improve disease symptoms. In 2014, a 45-year-old man presented with recurrent severe fasting and postprandial symptomatic hypoglycemia. The symptoms resolved after glucose ingestion. Fasting test was positive after only 4 $\mathrm{h}$ but imaging methods (abdominal computerized tomography, magnetic resonance imaging, endoscopic ultrasonography and octreotide scintigraphy) failed to identify pancreatic lesions. Hypoglycemia in face of endogenous hyperinsulinemia and lack of focal lesions in the pancreas in multiple imaging exams suggested the diagnosis of adult nesidioblastosis. The patient preferred conservative medical treatment in association with dietary recommendations. Nifedipine $(30 \mathrm{mg} /$ day $)$ did not improve the glycemic profile and was poorly tolerated by the patient. Diazoxide $150 \mathrm{mg} /$ day was started, with progressive increase to $400 \mathrm{mg}$ /day over 6 weeks. Patient has been successfully treated with medical treatment for 5 years, with no events of severe hypoglycemia, no significant side effects and with marked improvement in quality of life. This clinical case demonstrates that adult hyperinsulinemic hypoglycemia can be effectively controlled with medical treatment, which is a viable alternative to pancreatic surgery.
\end{abstract}

Keywords: Nesidioblastosis; Hyperinsulinemic hypoglycemia; Medical treatment; Diazoxide

\section{Introduction}

Hyperinsulinemic hypoglycemia $(\mathrm{HH})$ comprises a group of clinically, genetically and histologically heterogeneous disor-

Manuscript submitted October 14, 2019, accepted October 25, 2019

aEndocrinology, Diabetes and Metabolism Department, Santa Maria Hospital, Lisbon, Portugal

${ }^{b}$ Corresponding Author: Vania Gomes, Endocrinology, Diabetes and Metabolism Department, Santa Maria Hospital, Avenida Professor Egas Moniz, Lisbon 1649-035, Portugal. Email: vania.rodrigues.gomes@gmail.com

doi: https://doi.org/10.14740/jem617 ders, characterized by inappropriate insulin secretion from the pancreatic $\beta$ cells in the presence of low blood glucose (BG) levels [1]. In adults, $0.5-5 \%$ of hypoglycemias are due to $\mathrm{HH}$ [1]. The diagnosis of hypoglycemia is based on Whipple's triad (symptoms, signs or both consistent with hypoglycemia; a low reliably measured plasma glucose concentration $(<55 \mathrm{mg} / \mathrm{dL})$ at the time of suspected hypoglycemia; resolution of symptoms or signs when hypoglycemia is corrected) [2]. Hypoglycemia may have multiple etiologies: insulinoma, post-bariatric surgery, adult-onset nesidioblastosis, autoimmunity, medications, non-islet cell tumors, hormonal deficiencies, critical illness and factitious hypoglycemia [3]. Insulinoma is the most common cause of endogenous HH in adults. On the contrary, nesidioblastosis is a very rare cause of $\mathrm{HH}$ in this age group and the etiology is still not fully understood [4]. This condition is a functional and anatomical disorder of non-neoplastic $\beta$ cells characterized by hyperplasia, diffuse proliferation and hypertrophy of islet cells [5].

The majority of cases of adult-onset nesidioblastosis occurred after Roux-en-Y gastric bypass surgery and potential implicated mechanisms include: increased levels of incretins (glucagon-like peptide-1 (GLP-1) and gastric inhibitory peptide); improved $\beta$-cell sensitivity to GLP-1; absence of postsurgery reduction of islet cell mass/function; increased insulin sensitivity secondary to weight loss; inappropriate insulin hypersecretion and anomalous counter-regulatory hormonal response to hypoglycemia [6].

Nesidioblastosis is a possible cause of $\mathrm{HH}$ in individuals without previous history of bariatric surgery and negative localizing imaging studies. In this condition hypoglycemia usually arises in the postprandial period [3]. Treatment of nesidioblastosis includes the acute management of hypoglycemia and surgical or chronic medical treatment. Surgical treatment is the choice in patients with severe or refractory hypoglycemia. Prior to surgery, selective arterial calcium stimulation (SACST) should be done to determine whether the increased insulin secretion is focal or diffuse [7]. In cases where the imaging and functional tests fail to fully characterize the condition or the patient presents any contraindication to surgery, medical treatment can be considered. Long-term medical therapy comprises dietetic measures, alpha-glucosidase inhibitors, calcium channel blockers, diazoxide, and somatostatin analogues [1]. Dietary modifications might be sufficient to manage patients with mild postprandial hypoglycemic episodes [7, 8]. Treatment depends on the severity of hypoglycemic episodes. When medi- 
Table 1. Laboratory Tests

\begin{tabular}{lll}
\hline Parameter & Patient's 72-h fasting test & Endogenous hyperinsulinism [2] \\
\hline Insulin $(\mu \mathrm{U} / \mathrm{mL})$ & 6.4 & $\geq 3$ \\
Proinsulin $(\mathrm{pmol} / \mathrm{L})$ & 5.6 & $\geq 5$ \\
C-peptide $(\mathrm{nmol} / \mathrm{L})$ & 0.6 & $\geq 0.2$ \\
Beta-hydroxybutyrate $(\mathrm{mmol} / \mathrm{L})$ & $\leq 2.7$ & $\leq 2.7$ \\
\hline
\end{tabular}

cation is needed, diazoxide is the first-line medical therapy for long-term management [1].

We report a case of a 45-year-old man with $\mathrm{HH}$, probably nesidioblastosis, successfully treated with medical therapy.

\section{Case Report}

We report the case of a 45-year-old man, referenced to the endocrinology department of a tertiary hospital in 2014 for investigation of severe and recurrent hypoglycemia. The patient was a construction worker, so these hypoglycemic episodes were life-threatening. He reported fasting and postprandial symptoms of dizziness, impaired concentration, profuse sweating, and peripheral tremor. After food ingestion, symptoms reverted. In one of such episodes capillary BG was confirmed to be below $40 \mathrm{mg} / \mathrm{dL}$. Nevertheless, in routine blood analysis 2 years prior, he presented BG levels under $60 \mathrm{mg} / \mathrm{dL}$, but no further investigation was conducted then. He denied recent significant weight gain. Medical history was notable for pulmonary tuberculosis in 2011, cured after a prolonged course of combined tuberculostatic drugs, as well as vena cava thrombosis, diagnosed in the same year and treated with acenocoumarol $4 \mathrm{mg}$ /day since then. The patient denied previous surgical interventions, particularly bariatric or gastric procedures and previous diagnosis of diabetes or surreptitious intake of insulin or oral hypoglycemic agents. He admitted having regular moderate consumption of alcoholic beverages ( $48 \mathrm{~g}$ of alcohol per day). Physical examination was unremarkable.

Laboratory tests showed normal thyroid, adrenal and liver function. Liver ultrasonography was also normal. Glycated hemoglobin was $4.0 \%$ and ambulatory self-monitoring of capillary glucose confirmed low BG levels in fasting state $(30-60 \mathrm{mg} / \mathrm{dL})$ and postprandially $(55-90 \mathrm{mg} / \mathrm{dL})$, even after implementation of a low carbohydrate seven-meal diet plan. The 72-h fasting test led to the fulfillment of Whipple's triad after only $4 \mathrm{~h}$ (BG of $45 \mathrm{mg} / \mathrm{dL})$. At that time, we documented elevated insulin, proinsulin and C-peptide and low beta-hydroxybutyrate (Table 1) [2], indicative of endogenous hyperinsulinism. Thirty minutes after glucagon administration plasma glucose rose to $79 \mathrm{mg} / \mathrm{dL}$, increasing more than $25 \mathrm{mg} / \mathrm{dL}$. Anti-insulin and insulin receptors antibodies were negative, as was also the test for detection of sulfonylureas. Insulinoma was suspected and imaging localization studies were requested. However, imaging studies, namely abdominal computerized tomography (CT), magnetic resonance imaging (MRI), endoscopic ultrasonography and octreotide scintigraphy failed to identify pancreatic lesions.

Hypoglycemia in face of endogenous hyperinsulinemia and lack of focal lesions in the pancreas in multiple imaging exams suggested the diagnosis of adult nesidioblastosis. The patient was hesitant toward any further invasive procedure as SACST and surgery. He opted for conservative medical treatment in association with dietary recommendations. A short trial with nifedipine $30 \mathrm{mg}$ per day resulted in no amelioration of hypoglycemia and intolerable side effects of headache and peripheral edema. Treatment with diazoxide $150 \mathrm{mg} /$ day was started, with progressive increase to $400 \mathrm{mg}$ /day over 6 weeks. Patient now presents fasting glycemia of $78-86 \mathrm{mg} / \mathrm{dL}$ and 90 $115 \mathrm{mg} / \mathrm{dL}$ postprandially. Blood pressure levels remain within normal range and the patient reports no diazoxide-related side effects. Patient has been successfully treated with diazoxide for 5 years with marked improvement in quality of life.

\section{Discussion}

Distinction between adult nesidioblastosis and an occult insulinoma can be difficult, due to the similarity of the biochemical profile and some overlap in clinical presentation. The main clinical feature of nesidioblastosis is postprandial hypoglycemia, although fasting hypoglycemia has also been reported, as is typical in patients with insulinoma $[9,10]$. The definitive diagnosis relies on anatomical localization and histological examination of the pancreatic tissue $[10,11]$.

Nesidioblastosis is suspected in patients with $\mathrm{HH}$ and negative imaging studies, as we presented in this clinical case. Localization imaging studies comprise CT, MRI, transabdominal ultrasonography and somatostatin receptor scintigraphy, as well as more invasive studies (endoscopic ultrasonography and SACST) [3]. Besides, emerging GLP-1 receptor-based imaging with ${ }^{68} \mathrm{Ga}$-DOTA-exendin-4 positron emission tomography-computed tomography (PET-CT) has been used for insulinoma localization in a few studies [12].

When these methods fail to identify a focal lesion, SACST with hepatic venous sampling is important to establish that the hyperinsulinemia has a pancreatic origin and its regionality within the pancreas [13]. This procedure can support nesidioblastosis diagnosis and guide surgical procedures in cases where pancreatic excision is considered [7]. In the clinical case presented, patient refused further invasive procedures and surgery. Considering patient's wishes as well as the risks involved in the catheterization procedure and pancreatic surgery, we decided for medical treatment.

The severity of hypoglycemia should guide the treatment. Dietary recommendations (reduction of free carbohydrate intake and fractionated carbohydrate intake throughout the day) can reduce postprandial glycemic excursions and fasting hypoglyce- 
mia and could be enough to treat cases of mild hypoglycemia $[7,8]$. If dietary measures are not sufficient, pharmacological treatment with diazoxide, alpha-glucosidase inhibitors, calcium channel blockers or somatostatin analogues should be considered. Diazoxide is the standard medical treatment, inhibiting insulin secretion by opening the adenosine triphosphate (ATP)dependent potassium channel of the pancreatic $\beta$ cells, but its side effect profile can limit its use [14]. The more serious side effects are sodium and fluid retention leading to cardiac failure, diabetic ketoacidosis and nonketotic hyperosmolar coma, pulmonary hypertension, thrombocytopenia and neutropenia [14]. Non-serious side effects include hypertrichosis, anorexia, nausea and vomiting, and hyperuricemia [14]. Diazoxide is given orally as $3-8 \mathrm{mg} / \mathrm{kg} /$ day divided every $8-12 \mathrm{~h}[14,15]$.

Somatostatin receptor (SSTR) ligands such as octreotide and lanreotide inhibit insulin secretion when given in high doses but may not be as effective as diazoxide [15]. The weak binding affinity and the limited range of SSTRs covered by these drugs impair their efficacy [16]. This therapy is a second-line option for refractory insulinomas and nesidioblastosis [16]. Pasireotide, a multi-SSTR ligand (SSRT 1, 2, 3 and 5), has been developed for the treatment of gastroenteropancreatic neuroendocrine tumors and there are a few reports of successfully long-term management of adult nesidioblastosis [17-19].

Insulin secretion is calcium dependent, thus calcium-channel blockade at the $\beta$-cell membrane can disrupt insulin release [20]. Calcium-channel blockers as verapamil, diltiazem and amlodipine may be used as potential therapeutic agents in cases of nesidioblastosis [20]. However, the use of first generation calcium antagonists (verapamil, nifedipine) may be limited by their side effect profile, including headache, flushing, bradycardia, and hypotension [20].

Alpha-glucosidase inhibitors, such as acarbose, delay the digestion of carbohydrates, resulting in lower BG concentrations after meals [21]. They have been successfully used in patients with post-bariatric surgery hypoglycemia, but its role in the management of adult-onset diffuse nesidioblastosis is not clearly established [21, 22].

In patients developing severe or refractory symptoms, surgical treatment might be required. When there is diffuse $\beta$-cell involvement, subtotal pancreatectomy is indicated, while in the focal type, partial pancreatectomy is the procedure of choice [23].

In the reported clinical case, we performed a trial with nifedipine, but this drug was poorly tolerated by the patient. He presented headache and peripheral edema without any improvement of hypoglycemia episodes. Medical treatment with diazoxide complemented with dietary recommendations reestablished and maintained normoglycemia and a good quality of life for the patient for 5 years.

There are very few reports of medical treatment of $\mathrm{HH}$ in adults. This clinical case shows that adult HH can be successfully treated, with limited side effects, with diazoxide, which can be considered as an alternative to pancreatic surgery.

\section{Acknowledgments}

We would like to thank the patient for his approval for publica- tion of this case report.

\section{Financial Disclosure}

None to declare.

\section{Conflict of Interest}

None to declare.

\section{Informed Consent}

Not applicable.

\section{Author Contributions}

VG collected the data and wrote the manuscript; FF was the endocrinologist in charge of the patient's care and reviewed the manuscript for important intellectual content.

\section{References}

1. Shah P, Rahman SA, Demirbilek H, Guemes M, Hussain $\mathrm{K}$. Hyperinsulinaemic hypoglycaemia in children and adults. Lancet Diabetes Endocrinol. 2017;5(9):729-742.

2. Cryer PE, Axelrod L, Grossman AB, Heller SR, Montori VM, Seaquist ER, Service FJ, et al. Evaluation and management of adult hypoglycemic disorders: an Endocrine Society Clinical Practice Guideline. J Clin Endocrinol Metab. 2009;94(3):709-728.

3. Kittah NE, Vella A. MANAGEMENT OF ENDOCRINE DISEASE: Pathogenesis and management of hypoglycemia. Eur J Endocrinol. 2017;177(1):R37-R47.

4. Demirbilek H, Rahman SA, Buyukyilmaz GG, Hussain $\mathrm{K}$. Diagnosis and treatment of hyperinsulinaemic hypoglycaemia and its implications for paediatric endocrinology. Int J Pediatr Endocrinol. 2017;2017:9.

5. Davi MV, Pia A, Guarnotta V, Pizza G, Colao A, Faggiano A, On behalf of NIKE Group. The treatment of hyperinsulinemic hypoglycaemia in adults: an update. J Endocrinol Invest. 2017;40(1):9-20.

6. Eisenberg D, Azagury DE, Ghiassi S, Grover BT, Kim JJ. ASMBS position statement on postprandial hyperinsulinemic hypoglycemia after bariatric surgery. Surg Obes Relat Dis. 2017;13(3):371-378.

7. Arnold R, Rinke A, Anlauf M. Persistent hyperinsulinemic hypoglycemia (PHH) in adults: insulinoma and nesidioblastosis. In: Modlin IM, Oberg K. A century of advances in neuroendocrine tumor biology and treatment. Hannover, Felsenstein CCCP. 2008; p. 76-83.

8. Kellogg TA, Bantle JP, Leslie DB, Redmond JB, Slusarek B, Swan T, Buchwald H, et al. Postgastric bypass hyperinsulinemic hypoglycemia syndrome: characterization 
and response to a modified diet. Surg Obes Relat Dis. 2008;4(4):492-499.

9. Starke A, Saddig C, Kirch B, Tschahargane C, Goretzki P. Islet hyperplasia in adults: challenge to preoperatively diagnose non-insulinoma pancreatogenic hypoglycemia syndrome. World J Surg. 2006;30(5):670-679.

10. Dravecka I, Lazurova I. Nesidioblastosis in adults. Neoplasma. 2014;61(3):252-256.

11. Kowalewski AM, Szylberg L, Kasperska A, Marszalek A. The diagnosis and management of congenital and adultonset hyperinsulinism (nesidioblastosis) - literature review. Pol J Pathol. 2017;68(2):97-101.

12. Christ E, Wild D, Antwi K, Waser B, Fani M, Schwanda S, Heye T, et al. Preoperative localization of adult nesidioblastosis using ${ }^{68} \mathrm{Ga}-\mathrm{DOTA}-$ exendin-4-PET/CT. Endocrine. 2015;50(3):821-823.

13. Thompson SM, Vella A, Thompson GB, Rumilla KM, Service FJ, Grant CS, Andrews JC. Selective arterial calcium stimulation with hepatic venous sampling differentiates insulinoma from nesidioblastosis. J Clin Endocrinol Metab. 2015;100(11):4189-4197.

14. Thornton P, Truong L, Reynolds C, Hamby T, Nedrelow J. Rate of serious adverse events associated with diazoxide treatment of patients with hyperinsulinism. Horm Res Paediatr. 2019;91(1):25-32.

15. Desimone ME, Weinstock RS. Non-Diabetic Hypoglycemia. In: Feingold KR, Anawalt B, Boyce A, Chrousos G, Dungan K, Grossman A, Hershman JM, et al., editors. Endotext. South Dartmouth (MA) 2000.

16. Dauriz M, Maneschi C, Castelli C, Tomezzoli A, Fuini A, Landoni L, Malleo $\mathrm{G}$, et al. A case report of insulinoma relapse on background nesidioblastosis: a rare cause of adult hypoglycemia. J Clin Endocrinol Metab.
2019;104(3):773-778.

17. Bruns C, Lewis I, Briner U, Meno-Tetang G, Weckbecker G. SOM230: a novel somatostatin peptidomimetic with broad somatotropin release inhibiting factor (SRIF) receptor binding and a unique antisecretory profile. Eur J Endocrinol. 2002;146(5):707-716.

18. Cives M, Kunz PL, Morse B, Coppola D, Schell MJ, Campos T, Nguyen PT, et al. Phase II clinical trial of pasireotide long-acting repeatable in patients with metastatic neuroendocrine tumors. Endocr Relat Cancer. 2015;22(1):1-9.

19. Schwetz V, Horvath K, Kump P, Lackner C, Perren A, Forrer F, Pieber TR, et al. Successful medical treatment of adult nesidioblastosis with pasireotide over 3 years: a case report. Medicine (Baltimore). 2016;95(14):e3272.

20. Martin-Grace J, O'Tuathail M, Hannon MJ, Swan N, O'Shea D, Tamagno G. Amlodipine for the Medical Treatment of Adult-Onset Diffuse Nesidioblastosis. Pancreas. 2015;44(7):1162-1164.

21. Malik S, Mitchell JE, Steffen K, Engel S, Wiisanen R, Garcia L, Malik SA. Recognition and management of hyperinsulinemic hypoglycemia after bariatric surgery. Obes Res Clin Pract. 2016;10(1):1-14.

22. Ritz P, Vaurs C, Bertrand M, Anduze Y, Guillaume E, Hanaire $\mathrm{H}$. Usefulness of acarbose and dietary modifications to limit glycemic variability following Roux-en-Y gastric bypass as assessed by continuous glucose monitoring. Diabetes Technol Ther. 2012;14(8):736-740.

23. Thompson GB, Service FJ, Andrews JC, Lloyd RV, Natt $\mathrm{N}$, van Heerden JA, Grant CS. Noninsulinoma pancreatogenous hypoglycemia syndrome: an update in 10 surgically treated patients. Surgery. 2000;128(6):937-944;discussion 944-935. 